\title{
La dimension poétique du texte chez La Fontaine (Les Fables)
}

Mohmmed El Sagheer Abou Elkassem Maître de conférences à la faculté des lettres Département de français

Université d'Assouan 
Au sens premier, la fable est un texte court qui s'intéresse à présenter de façon amusante une leçon de vie. «Elle est...une des formes les plus anciennes de la pensée humaine exprimée d'une manière brève et sententieuse ${ }^{1} \gg$. Ce récit imaginaire se caractérise par une composition allégorique où les personnages varient : des animaux, des êtres humains ou des choses mais tous doivent être en personnifiés ${ }^{2}$. Définissant cette entreprise, La Fontaine écrit :

\section{«Cependant jusqu'ici d'un langage nouveau J'ai fait parler le Loup et répondre l'Agneau. J'ai passé plus avant : les Arbres et les Plantes Sont devenus chez moi créatures parlantes. Qui ne prendrait ceci pour un enchantement ? $^{3}$ »}

Entre l'ancien et le moderne, les visions sur l'art de la fable se sont multipliées. Selon Gilbert Keith Chesterton, « la fable est une sorte d'alphabet de l'humanité au moyen duquel on a pu écrire les premières certitudes philosophiques; et pour cette raison les figures devaient fonctionner comme des abstractions algébriques ou des pièces d'un jeu d'échecs ${ }^{4}$.» Dès la seconde moitié du XXème siècle, les fables deviennent bien moins populaires. Elles ont été remplacées par la télévision, par la radio et par l'internet. Ceci leur fait perdre leurs valeurs scolaires. À ce propos, Fabrice Lucchini a dit : «Il y a longtemps que les fables ne nous intéressent plus pour leur moralité. N'importe quel gamin vous le dira : le plaisir, c'est l'histoire, et peu importe la leçon ! $!^{5}$ Cette vision philosophique n'a été adoptée que par quelques écrivains. Pour la plupart, le récit et la morale se complètent. Ils représentent également un élément essentiel de la composition de la fable. Alors, ils doivent être s'y mélangés. Cette théorie apparait chez Esope, Horace, Marie de France et Phèdre, ce dernier insiste sur l'idée que « le mérite de la

\footnotetext{
${ }^{1}$ Scholl (Jules-Charles), «Le Fable et les fabulistes », article, Actes de la Société jurassienne d'émulation, 2019, p. 120.

${ }^{2}$ Van Gennep (Arnold), « Manuel de folklore français contemporain », A. Picard, Paris, 1938, p. 741.

${ }^{3}$ La Fontaine (Jean de), “Euvres Complètes”, Seuil, Paris, 1965, P.82.

${ }^{4}$ Van der Meulen (Emmanuel) \& Zarka (Raphaël), «FABLES, FORMES, FIGURES », Fondation Nationale des Arts Graphiques et Plastiques, juin 2018. Sur le site : https://www.fondationdesartistes.fr/wp-content/uploads/2019/02/cp-FablesFormes-Figures.pdf.

${ }^{5}$ http://lettres-histoire-

geo.acamiens.fr/IMG/pdf/la_fable_et_le_conte_pour_argumenter.
} 
fable est double : elle suscite le rire et donne une leçon de prudence ${ }^{1} »$. Dans la préface de son premier livre, La Fontaine résout cette question controversée en affirmant que «l'apologue est composé de deux parties, dont on peut appeler l'une le corps, l'autre l'âme ; le corps est la fable ; l'âme, la moralité ${ }^{2} »$. Pour lui, la fable est une incarnation d'une vie pleine d'actions, d'ennuis, de joies et de destins. Elle représente l'homme avec ses qualités et ses défauts. De même, ces histoires n'ont cessé de conserver des valeurs pédagogiques qui racontent non seulement notre passé, mais qui ont pour but d'illuminer notre avenir.

Dans ces circonstances difficiles qu'on vit aujourd'hui, on a beaucoup besoin de relire ces fables qui nous aident à comprendre la vie, qui sont « un tableau où chacun de nous se trouve dépeint ${ }^{3}$ ». Nous ne les lirons pas en tant qu'un genre littéraire destiné au divertissement, mais nous favoriserons une lecture orientée par la recherche des signes de la preuve poétique du conteur ${ }^{4}$. Alors, nous tenterons de découvrir ces signes en répondant aux questions suivantes : qui sont les héros des fables ? Quels sont les compositions et les thèmes du dialogue ? Les procédés d'écriture sont considérés comme l'un des outils que le moraliste emploie pour affirmer sa poétique et approfondir sa pensée, Comment ? Où préfère le poète de mettre sa moralité ? Le poète jette directement ou indirectement ses idées? Le paradoxe est l'une des caractéristiques de la fable, Comment? La Fontaine tente de tracer un univers idéalisé ou réel ? Deux directions qu'on peut donc suivre afin de déchiffrer les visages multiples du génie poétique de La Fontaine, ce sont le récit et la moralité :

\section{I- Le récit :}

Tout d'abord, nous pouvons dire que la poétique du récit lafontainien apparaît à travers ce triple : le personnage, le dialogue et l'écriture :

${ }^{1}$ manpowergroup.com.br/jolies_fables_de_la_fontaine.pdf

${ }^{2}$ La Fontaine (Jean de), “CEuvres Complètes”, Op.cit., P. 63.

${ }^{3}$ Fiechi (Hélène), « Jean de La Fontaine, Fables », Gallimard, Paris, 2000, P. 172.

${ }^{4}$ Dandrey (Patrick), « La fabrique des fables. Essai sur la poétique de La

Fontaine », Paris, Klincksieck, coll. « Théorie et critique de l'âge classique », nO 6, 1991. 


\section{1) L'intervention des personnages :}

Parce que l'écrivain cherche à réformer le comportement humain, à pousser la nature humaine envers le bien, la paix, la coopération, la modestie, la bonté et la pureté, il nous offre donc des personnages de fous et non des figures exemplaires pour les rendre meilleurs et pour les instruire. Parmi ces modèles, les fables mettent en scène des animaux qui parlent et symbolisent les hommes. Quand la cigale chante, la fourmi cherche à l'accompagner :

« La Cigale, ayant chanté

Tout l'Été,

Se trouva fort dépourvue

Quand la bise fut venue.

Pas un seul petit morceau

De mouche ou de vermisseau.

Elle alla crier famine

Chez la Fourmi sa voisine,

La priant de lui prêter

Quelque grain pour subsister

Jusqu'à la saison nouvelle. ${ }^{1}$ »

Le corbeau et le renard se parlent aussi :

«Maître Corbeau, sur un arbre perché,

Tenait en son bec un fromage.

Maître Renard, par l'odeur alléché,

Lui tint à peu près ce langage :

Et bonjour, Monsieur du Corbeau. ${ }^{2}$ »

Dans ce court récit, les exemples des animaux qui se rencontrent pour discuter sont nombreux. On trouve aussi le loup et le chien :

«Le Loup reprit : "Que me faudra-t-il faire?

- Presque rien, dit le Chien, donner la chasse aux gens

Portants bâtons, et mendiants ;

Flatter ceux du logis, à son Maître complaire :

Moyennant quoi votre salaire

Sera force reliefs de toutes les façons :

Os de poulets, os de pigeons,

Sans parler de mainte caresse. ${ }^{3}$ »

${ }^{1}$ La Fontaine (Jean de), “CEuvres Complètes”, Op.cit., P. 75.

${ }^{2}$ Loc.cit.

${ }^{3}$ La Fontaine (Jean de), “CEuvres Complètes”, Op.cit., P. 76. 
Le loup parle aussi avec l'agneau :

«Un Loup survient à jeun, qui cherchait aventure,

Et que la faim en ces lieux attirait.

Qui te rend si hardi de troubler mon breuvage ?...

Tu seras châtié de ta témérité.

Sire, répond l'Agneau, que Votre Majesté

Ne se mette pas en colère ${ }^{1}$ »

Outre la Génisse, la Chèvre et la Brebis, l'Hirondelle et les petits Oiseaux, le Rat de ville et le Rat des Champs, le Renard et la Cigogne, les Frelons et les Mouches à miel, les animaux peuvent aussi se déguiser en hommes : un singe manque d'être sauvé de la noyade à cause de la ressemblance avec un humain, mais quand il est démasqué par le dauphin, celui-ci le rejette à l'eau :

«Il sauva donc tout ce qu'il put. Même un Singe en cette occurrence, Profitant de la ressemblance, Lui pensa devoir son salut.

Un Dauphin le prit pour un homme, Et sur son dos le fit asseoir Si gravement qu'on eût cru voir Ce chanteur que tant on renomme. »

Dans «Le loup devenu berger », le fabuliste met en scène un loup qui, pour subvenir à ses besoins, se déguise en berger :

«Un loup, qui commençait d'avoir petite part Aux brebis de son voisinage, Crut qu'il fallait s'aider de la peau du renard, Et faire un nouveau personnage. Il s'habille en berger, ............ »

La « diversité, c'est la devise ${ }^{2}$ » de La Fontaine qui essaie d'élargir son fable. Outre les animaux, il met aussi en scène beaucoup de personnages humains comme «L'Homme et son image » :

\footnotetext{
${ }^{1}$ Ibid., P. 78.

${ }^{2}$ Bortoli (Véronique Bremond), « Fables, (livres VII à IX) », Hachette, Paris, 2017, P. 9.
} 
«Un Homme qui s'aimait sans avoir de rivaux

Passait dans son esprit pour le plus beau du monde :

Il accusait toujours les miroirs d'être faux, Vivant plus que content dans son erreur profonde. ${ }^{1}$ »

Dans «L'Enfant et le Maître d'école », il ajoute :

«Un jeune Enfant dans l'eau se laissa choir,

En badinant sur les bords de la Seine.

Le Ciel permit qu'un saule se trouva

Dont le branchage, après Dieu, le sauva.

S'étant pris, dis-je, aux branches de ce saule,

Par cet endroit passe un Maître d'école ;

L'enfant lui crie : Au secours, je péris. ${ }^{2}{ }^{\text {» }}$

Les humains et les animaux se parlent également dans ces récits. Ils dialoguent ensemble et se comprennent :

«Pour un Âne enlevé deux Voleurs se battaient :

L'un voulait le garder, l'autre le voulait vendre. ${ }^{3}{ }^{\prime}$

Quand les animaux rencontrent les choses, La fontaine écrit :

«A l'œuvre on connaît l'artisan.

Quelques rayons de miel sans maître se trouvèrent,

Des Frelons les réclamèrent,

Des Abeilles s'opposant,

Devant certaine Guêpe on traduisit la cause. ${ }^{4}{ }$ '

Dans ces spectacles divers où les personnages s'énumèrent, les éléments naturels jouent encore le rôle d'un de ces héros. Le Chêne dit un jour au Roseau :

«Vous avez bien sujet d'accuser la Nature ;

Un Roitelet pour vous est un pesant fardeau.

Le moindre vent, qui d'aventure

Fait rider la face de l'eau,

Vous oblige à baisser la tête :

${ }^{1}$ La Fontaine (Jean de), “EEuvres Complètes”, Op.cit., P. 78.

${ }^{2}$ Ibid. P. 81.

${ }^{3}$ Ibid. P. 79.

${ }^{4}$ Ibid. P.81. 
Cependant que mon front, au Caucase pareil, Non content d'arrêter les rayons du soleil, Brave l'effort de la tempête. ${ }^{1}{ }^{\prime}$

Les héros sont également des dieux et des hommes :

« Un Malheureux appelait tous les jours

La mort à son secours;

Ô Mort, lui disait-il, que tu me sembles belle !

Viens vite, viens finir ma fortune cruelle.

La mort crut en venant, l'obliger en effet.

Elle frappe à sa porte, elle entre, elle se montre.

Que vois-je ! cria-t-il, ôtez-moi cet objet;

Qu'il est hideux ! que sa rencontre

Me cause d'horreur et d'effroi !

N'approche pas, ô Mort ; ô Mort, retire-toi. ${ }^{2}$ »

Dans «La Mort et le Bûcheron », le fabuliste ajoute :

«Un pauvre bûcheron, tout couvert de ramée, Sous le faix du fagot aussi bien que des ans

Gémissant et courbé, marchait à pas pesants, Et tâchait de gagner sa chaumine (1) enfumée. Enfin, n'en pouvant plus d'effort et de douleur,

Il met bas son fagot, il songe à son malheur. Quel plaisir a-t-il eu depuis qu'il est au monde ? En est-il un plus pauvre en la machine ronde?

Point de pain quelquefois, et jamais de repos. ${ }^{3}$ "

Les héros sont en fin des animaux et des dieux comme l'auteur le montre dans sa fable « La Besace » :

« Jupiter dit un jour : Que tout ce qui respire S'en vienne comparaître aux pieds de ma grandeur.

Si dans son composé quelqu'un trouve à redire,

Il peut le déclarer sans peur :

Je mettrai remède à la chose.

Venez, Singe ; parlez le premier, et pour cause.

\footnotetext{
${ }^{1}$ La Fontaine (Jean de), “CEuvres Complètes”, Op.cit., P. 81.

${ }^{2}$ Ibid. P. 76.

${ }^{3}$ Loc. cit.
} 


\section{Voyez ces animaux, faites comparaison De leurs beautés avec les vôtres ${ }^{1}$ »}

La diversité et le contraste dynamique ${ }^{2}$ de ces héros fictifs nous amèneront donc à tenter de déchiffrer les mystères du dialogue, ces narrations qui reflètent, comme nous le voyons, la volonté du fabuliste à tracer un tableau réaliste d'une vie où la lutte représente l'un de ses éléments.

2- Le dialogue «Tout parle en mon ouvrage, et même les poissons ${ }^{3} »$ :

Pour réaliser ses deux buts, créer un spectacle dynamique et exciter le lectorat de poursuivre sa lecture, La Fontaine privilégie, dans ces histoires dramatiques, le chant des événements et des aventures ainsi qu'il mêle d'une merveilleuse harmonie l'animal, la chose et l'être humain et les fait dialoguer ensemble. À cet égard, nous constatons que le dialogue dans ces récits (Le loup et l'agneau/ Le chêne et le roseau comme exemples) est caractérisé par :

A-) La variété des personnages et des circonstances (qui ?, où ?, quand ?, comment ?). Dans « Le loup et l'agneau », on peut lire cette composition :

\begin{tabular}{|l|l|}
\hline Les personnages & $\begin{array}{l}\text { 1) Le loup\& } \\
\text { L'agneau }\end{array}$ \\
\hline Les qualités & $\begin{array}{l}\text { Opposés : Tu (l'innocence de l'agneau) } \\
\text { votre majesté (la cruauté du loup) }\end{array}$ \\
\hline Le lieu & Une rivière - la forêt \\
\hline Le moment & A l'aube (onde pure/ à jeun) \\
\hline Les événements & $\begin{array}{l}\text {-Un Agneau se désaltérait } \\
\text {-Un Loup ......... cherchait aventure }\end{array}$ \\
\hline
\end{tabular}

En poursuivant l'itinéraire du dialogue entre ces deux animaux, on peut remarquer que l'inégalité et l'injustice dominent le spectacle :

${ }^{1}$ La Fontaine (Jean de), “CEuvres Complètes”, Op.cit., P.76.

${ }^{2}$ Collinet, (J. P), « Le monde littéraire de La Fontaine ». Slatkine Reprints , 1970,

P.161. sur le site : https://openaccess.leidenuniv.nl/bitstream/handle/

${ }^{3}$ http://www.site-magister.com/prepas/fables2.htm\#axzz5kWB0h5De 
1) Ce sont deux bêtes opposés: l'agneau est encore petit «Je tête encore ma mère » tandis que le loup est grand «...tu médis l'an passé»; le loup s'adresse à l'agneau utilisant le pronom «Tu » qui affirme sa supériorité, tandis que l'agneau lui répond par l'emploi des termes comme « vous, votre, majesté, sire » qui indiquent sa faiblesse et son respect. Outre leur âge et leur façon de s'exprimer, l'opposition apparait également par l'usage des temps verbaux : afin de souligner le calme de l'agneau, le poète recourt à l'emploi de l'imparfait, alors que le présent «survient» traduit la rapidité et l'agressivité du loup. Par cette opposition qu'il trace, La Fontaine nous invite à lire le conflit infini entre le bien et le mal.

2-) Cette manière de communiquer entre les deux animaux insiste sur une seule idée : la dureté et la fausseté des accusations que le loup jette envers l'agneau. Pour le loup, l'agneau est toujours accusé de troubler le breuvage. Si ce n'est lui, c'est son frère, il le fait même s'il n'était pas né. "Cette bête cruelle » répète son accusation sans tenir compte des arguments de l'agneau.

3-) Le loup est à la fois l'accusateur et le juge. Pour mieux abuser l'agneau, il présente des argumentations raisonnables reposant sur des relations logiques : la cause (car...), la conséquence (donc...), l'addition (et...) et la concession (si ce n'est toi......).

4-) Malgré toutes ces accusations, l'agneau montre son respect pour son interlocuteur ainsi qu'il lui présente des preuves certaines de son innocence :

\begin{tabular}{|l|l|l|}
\hline $\begin{array}{l}\text { Argument } \\
\text { géographique }\end{array}$ & $\begin{array}{l}\text { Argument } \\
\text { chronologique }\end{array}$ & Argument familial \\
\hline Il est situé en aval & Il n'était pas né & Il est fils unique \\
\hline
\end{tabular}

5- ) Faire comparer les répliques du loup et celles de l'agneau, le lecteur peut toucher ces vérités: le loup n'attend pas la réponse pertinente et réfléchie de l'agneau qui apparaît naïf. La fin de la scène est fixée dès le début du dialogue comme le marque le futur: "Tu seras châtié". Face à cette agressivité aveugle du loup, les répliques de l'agneau deviennent de plus en plus courtes, affirmant l'inutilité de

la parole. Cette conclusion peut être clarifiée à travers le tableau suivant : 


\begin{tabular}{|l|l|}
\hline Le loup (l'accusation) & L'agneau (la défense) \\
\hline $\begin{array}{l}\text { Qui te rend si hardi de } \\
\text { troubler mon breuvage? }\end{array}$ & Plus de vingt pas au-dessous d'Elle ; \\
\hline $\begin{array}{l}\text { Et je sais que de moi tu médis } \\
\text { l'an passé. }\end{array}$ & $\begin{array}{l}\text { Comment l'aurais-je fait si je n'étais } \\
\text { pas né ? }\end{array}$ \\
\hline $\begin{array}{l}\text { Si ce n'est toi, c'est donc ton } \\
\text { frère. }\end{array}$ & Je n'en ai point. \\
\hline $\begin{array}{l}\text { C'est donc quelqu'un des } \\
\text { tiens: }\end{array}$ & $\ldots \ldots \ldots \ldots \ldots \ldots \ldots \ldots \ldots \ldots \ldots \ldots \ldots \ldots \ldots \ldots \ldots \ldots \ldots \ldots \ldots \ldots \ldots \ldots \ldots \ldots \ldots \ldots \ldots \ldots \ldots \ldots \ldots \ldots \ldots \ldots \ldots \ldots \ldots \ldots \ldots \ldots \ldots \ldots \ldots \ldots \ldots$ \\
\hline $\begin{array}{l}\text { il faut que je me venge. } \\
\text { Le loup l'emporte et puis le } \\
\text { mange, }\end{array}$ & $\ldots \ldots \ldots \ldots \ldots \ldots \ldots \ldots$ \\
\hline
\end{tabular}

La Fontaine essaie toujours de dessiner un dialogue justifiant, sincère et convaincant. Dans «Le Chêne et le Roseau », le poète, pour réincarner le conflit entre la faiblesse et la force, nous présente une série des répliques des deux personnages opposés :

\section{1- ) Le chêne :}

Entre les replis du dialogue, nous pouvons lire la prédominance du chêne qui possède le pouvoir avec le nombre des vers, les effets de syntaxe, les hyperboles et l'emploi de la première personne. Pour atteindre la moralité, l'épreuve est toujours la meilleure solution. Dès le premier moment de la rencontre, le chêne annonce hyperboliquement sa force :

\section{«Cependant que mon front, au Caucase pareil ${ }^{1}$ »}

La réplique du chêne se développe jusqu'à atteindre l'arrogance. Cette figure semble claire avec l'emploi des expressions comme " non content d'arrêter les rayons du soleil », «brave l'effort de la tempête ", « tout me semble zéphyr », « je couvre », « je vous défendrais ». De plus, le chêne arrive à dénoncer la nature, ou bien le destin: «accuser la nature », «si vous naissiez », "mais vous naissiez », «nature bien injuste ». Ce désir arrogant de domination et d'écrasement parait de même de la comparaison qu'il fait avec le Roseau :

\footnotetext{
${ }^{1}$ La Fontaine (Jean de), “CEuvres Complètes”, Op.cit., P. 81.
} 
« Tout vous est Aquilon, tout me semble Zéphyr. ${ }^{1}$ »

Pour terminer ces répliques qui n'affirment que la fierté, le chêne éprouve de la pitié envers le roseau. Cette sensation paraît hypocrite et moqueuse. Au temps où il propose ses services au roseau, le chêne ne peut rien faire :

\section{« Je vous défendrais de l'orage ${ }^{2}$ »}

\section{2- ) Le Roseau :}

Dans le voyage de la lutte continuelle entre la bonté et l'agressivité, La fontaine trace beaucoup d'exemples qui affirment toujours la même idée : la victoire de la logique. Pour faire approfondir cette pensée philosophique dans la mémoire du temps, le fabuliste fixe le regard sur deux mondes opposés. Outre les arguments de l'agneau, c'est au tour du roseau qui fait des efforts pour vaincre d'une manière logique l'arrogance du chêne. Les phénomènes de cette opposition entre ces deux animaux paraissent pertinents. Face à la longueur de la parole du chêne, l'intervention du roseau est brève et simple. Contrairement au chêne, le roseau n'est pas égocentrique ainsi qu'il n'utilise pas des hyperboles. Si ces oppositions insistent sur la faiblesse du roseau, elles affirment de même que la faiblesse est apparente, car la force vient de la simplicité et de la franchise. Au moment où le chêne annonce sa charité envers le roseau, ce dernier montre qu'il est sûr de sa propre force :

\section{«Votre compassion, lui répondit l'Arbuste, Part d'un bon naturel ; mais quittez ce souci ${ }^{3}$ »}

\section{B-) La typographie :}

B-1) L'ouvertement des guillemets avant les premières paroles et le fermement à la fin :

Commençons de la pièce où l'agneau et le loup représentent l'incarnation d'un univers fondé sur les contraires. Après la scène préliminaire où le poète met sous les yeux du lecteur une description

${ }^{1}$ La Fontaine (Jean de), “CEuvres Complètes”, Op.cit., P. 81.

${ }^{2}$ Loc.cit.

${ }^{3}$ Loc. cit. 
$\mathrm{du}$ lieu, des circonstances et des personnages, les guillemets s'ouvrent sur la phrase de l'accusation qui est l'axe autour duquel se déroulent tous les événements. Avant l'annonce de la manière de mettre en œuvre le jugement, le fabuliste ferme les guillemets sur la déclaration du jugement dans ce procès. Lisant attentivement le rôle et l'importance expressifs des guillemets, on peut diviser cette fable en quatre scènes :

- Avant les guillemets : connaitre les circonstances, les personnages et le lieu des événements

- Après l'ouverture des guillemets : l'accusation et le dialogue (l'attaque et la défense).

- Avant le fermement des guillemets : le jugement.

- après les guillemets : exécuter le jugement (le loup mange l'agneau).

«Qui te rend si hardi de troubler mon breuvage?

On me l'a dit : il faut que je me venge. ${ }^{1}{ }^{\prime}$

Dans «Le chêne et le roseau », le fabuliste, certifiant son refus des attitudes de la prédominance, commence le deuxième vers par des guillemets ainsi qu'il attend vingt vers pour fermer ces guillemets. Mais avant le fermement, il donne aux lecteurs son conseil : on ne doit pas décider la force de quelqu'un ou la faiblesse de l'autre, peutêtre la faiblesse est superficielle :

« Vous avez bien sujet d'accuser la Nature;

\section{Mais attendons la fin. ${ }^{2}$ »}

B-2) L'emploi du tiret et le changement de locuteur :

${ }^{1}$ La Fontaine (Jean de), “CEuvres Complètes”, Op.cit., P. 78.

${ }^{2}$ Ibid. P. 81. 
La lecture profonde des fables de La Fontaine manifeste que «La souplesse et le naturel du style sont en réalité le fruit d'un grand travail où le poète a manifesté sa parfaite maîtrise de la langue et du vers. ${ }^{1} »$ Le tiret devient donc l'un de ces phénomènes essentiels de la typographie qui nous invite à se concentrer sur ces vers dialogués qui personnifient la parole de ces deux héros opposés :

«- Tu la troubles, reprit cette bête cruelle ;

- Comment l'aurais-je fait si je n'étais pas né ?

- Si ce n'est toi, c'est donc ton frère. - Je n'en ai point. - C'est donc quelqu'un des tiens ${ }^{2}$ "

De cette même manière, le poète, pour bien montrer le refus du roseau de la charité du chêne, pousse le lecteur à lire profondément cette tonalité de moquerie et d'hypocrisie :

$$
\text { «- Votre compassion, lui répondit l'Arbuste }{ }^{3} »
$$

Les exemples sont ainsi nombreux. Par le tiret, on peut aussi lire les stratégies argumentatives et antithétiques du loup qui cherche incessamment la liberté et du chien qui symbolise ceux dont la soif d'argent ne s'arrête que par l'esclavage :

«- Presque rien, dit le Chien : donner la chasse aux gens

- Peu de chose.

- Mais encore ? - Le collier dont je suis attaché

- Attaché ? dit le Loup : vous ne courez donc pas - Il importe si bien, que de tous vos repas ${ }^{4}$

C-) L'emploi des verbes de parole :

Les verbes de parole sont considérés comme l'un des moyens que le poète emploie afin de présenter une image vivante et un dialogue personnifié. Dans «Le loup et l'agneau », le fabuliste dessine un tableau des deux animaux dotés de la parole :

${ }^{1}$ La Fontaine (Jean), « Les fables », ADL, Montréal, 2015, P. 3.

${ }^{2}$ La Fontaine (Jean de), “CEuvres Complètes”, Op.cit., P. 78.

${ }^{3}$ Ibid. P. 81.

${ }^{4}$ Ibid. P. 76. 
«Qui te rend si hardi de troubler mon breuvage?

Dit cet animal plein de rage :

- Sire, répond l'Agneau, que Votre Majesté

- Tu la troubles, reprit cette bête cruelle ;

Reprit l'Agneau, je tette encore ma mère

On me l'a dit : il faut que je me venge. ${ }^{1}$ "

Le chêne engage aussi le dialogue. Les verbes de parole affirment cette domination :

« Le Chêne un jour dit au Roseau :

«Vous avez bien sujet d'accuser la Nature ;

Je vous défendrais de l'orage ;

- Votre compassion, lui répondit l'Arbuste,

Mais attendons la fin. » Comme il disait ces mots. ${ }^{2}$ »

Les verbes de parole utilisés dans les deux scènes précédentes montrent que Le loup et le chêne adoptent le même ton du dialogue car ils ont les mêmes qualités, et c'est aussi le même cas de l'agneau et du Roseau qui se participent à la même philosophie. Ces dialogues antithétiques paraissent dans le tableau ci-dessous :

\begin{tabular}{|l|l|l|l|}
\hline Le Loup & L'agneau & Le chêne & Le Roseau \\
\hline Dit & Répond & Dit & Répondit \\
Reprit & Reprit & Accuser & Défendrais \\
Dit & & & Disait \\
\hline
\end{tabular}

La lecture attentive du dialogue dans les fables de La Fontaine peut nous assurer les effets suivants :

1) La longueur de la parole reflète la faiblesse réelle tandis que la brièveté montre la force et la confiance.

2) Les effets de syntaxe, les champs lexicaux et les formes hyperboliques aident à approfondir la moralité du récit qui symbolise en effet le conflit éternel entre deux valeurs opposées.

\section{3- Procédés d'écriture :}

Les Fables sont écrites en vers variés, c'est-à-dire que la longueur du vers (alexandrin, octosyllabe, etc.) est adaptée à son sujet. La

${ }^{1}$ La Fontaine (Jean de), “CEuvres Complètes”, Op.cit., P. 78.

${ }^{2}$ Ibid. P. 81. 
Fontaine y crée des effets de rime et de rythme en jouant des changements de vers, des enjambements et des rejets ${ }^{1}$. Il a recourt à l'humour et à l'ironie au point qu'il adopte la même définition de Platon : « Le poète est chose légère, ailée ${ }^{2}$ ». Dans « La Cigale et la Fourmi », il incarne cette légèreté en traçant un spectacle hétérométriques en heptasyllabes et en trisyllabique:

« La Cigale, ayant chanté Tout l'été,

Se trouva fort dépourvue Quand la bise fut venue.

Pas un seul petit morceau

De mouche ou de vermisseau.

Elle alla crier famine

Chez la Fourmi sa voisine, La priant de lui prêter Quelque grain pour subsister Jusqu'à la saison nouvelle. Je vous paierai, lui dit-elle, Avant l'août, foi d'animal, Intérêt et principal. ${ }^{3}$ »

Dans «Le Corbeau et le Renard», il mêle les alexandrins et les octosyllabes:

« À ces mots le Corbeau ne se sent pas de joie,

Et pour montrer sa belle voix,

Il ouvre un large bec, laisse tomber sa proie.

Le Renard s'en saisit, et dit : Mon bon Monsieur,

Apprenez que tout flatteur

Vit aux dépens de celui qui l'écoute.

Cette leçon vaut bien un fromage sans doute.

Le Corbeau honteux et confus

Jura, mais un peu tard, qu'on ne l'y prendrait plus. ${ }^{4}$ »

\footnotetext{
${ }^{1}$ Fiechi (Hélène), « Jean de La Fontaine, Fables », Op.cit., P. 74.

${ }^{2}$ Deschoux (Marcel ), « Platon ou le jeu philosophique », Les belles lettres, Paris, 1980, P. 59.

${ }^{3}$ La Fontaine (Jean de), “CEuvres Complètes”, Op.cit., P. 75.

${ }^{4}$ La Fontaine (Jean de), “CEuvres Complètes”, Op.cit.,P.75.
} 
Ce même mélange des mètres apparait dans d'autres pièces comme «La Grenouille qui veut se faire aussi grosse que le bœuf », "Le Loup et le Chien », "La Génisse, la Chèvre et la Brebis en société avec le Lion », «La Besace », «L'Hirondelle et les petits Oiseaux », «L'Homme et son image », "Le Dragon à plusieurs têtes et le Dragons à plusieurs queues », "Les Voleurs et l'Ane», «Simonide préservé par les Dieux », «Le Renard et la Cigogne », «Les Frelons et les Mouches à miel ». Dans «Le Chêne et le Roseau », il dit :

«Mais attendons la fin. "Comme il disait ces mots,

Du bout de l'horizon accourt avec furie

Le plus terrible des enfants

Que le Nord eût portés jusque-là dans ses flancs.

L'Arbre tient bon ; le Roseau plie.

Le vent redouble ses efforts,

Et fait si bien qu'il déracine

Celui de qui la tête au Ciel était voisine

Et dont les pieds touchaient à l'Empire des Morts. ${ }^{1}$ "

Dans «Les deux Mulets », le fabuliste mêle les alexandrins, les décasyllabes et les octosyllabes :

« Deux Mulets cheminaient ; l'un d'avoine chargé ;

$L$ 'autre portant l'argent de la gabelle.

Celui-ci, glorieux d'une charge si belle,

N'eût voulu pour beaucoup en être soulagé.

Il marchait d'un pas relevé,

Et faisait sonner sa sonnette ;

Quand, l'ennemi se présentant,

Comme il en voulait à l'argent,

Sur le Mulet du fisc une troupe se jette,

Le saisit au frein, et l'arrête. ${ }^{2}$ »

Les alexandrins, les décasyllabes, les octosyllabes et les tétrasyllabes, ces mètres divers sont aussi incarnés dans «Le Loup et l'Agneau »:

«Sire, répond l'Agneau, que Votre Majesté

Ne se mette pas en colère ;

Mais plutôt qu'elle considère

Que je me vas désaltérant

Dans le courant,

Plus de vingt pas au-dessous d'Elle ;

\footnotetext{
${ }^{1}$ Ibid., P. 81.

${ }^{2}$ Ibid. P. 76.
} 
Et que par conséquent, en aucune façon,

Je ne puis troubler sa boisson.

Tu la troubles, reprit cette bête cruelle, Et je sais que de moi tu médis l'an passé. ${ }^{1}$ »

Dans «L'Homme entre deux âges et ses deux Maîtresses », La Fontaine emploie presque tous les mètres, les alexandrins, les décasyllabes, les octosyllabes, les heptasyllabes et les trisyllabiques :

«Un homme de moyen âge,

Et tirant sur le grison, Jugea qu'il était saison

De songer au mariage.

Il avait du comptant,

Et partant

De quoi choisir. Toutes voulaient lui plaire ;

En quoi notre Amoureux ne se pressait pas tant :

Bien adresser n'est pas petite affaire. ${ }^{2}$ "

D'ailleurs, La Fontaine présente des poèmes isométriques. En heptasyllabes, il écrit «Le Rat de ville et le Rat des Champs » :

«Autrefois le Rat de ville Invita le Rat des champs,

D'une façon fort civile, À des reliefs d'Ortolans.

Sur un Tapis de Turquie

Le couvert se trouva mis.

Je laisse à penser la vie

Que firent ces deux amis. ${ }^{3}$ "

La fable de «L 'Enfant et le Maître d'école » est versifiée en décasyllabes :

«L'enfant lui crie : Au secours, je péris.

Le Magister, se tournant à ses cris,

D'un ton fort grave à contretemps s'avise

De le tancer: Ah le petit Babouin!

\footnotetext{
${ }^{1}$ La Fontaine (Jean de), “CEuvres Complètes”, Op.cit., P. 78.

${ }^{2}$ Ibid. P. 80.

${ }^{3}$ Ibid. P. 77.
} 
Voyez, dit-il, où l'a mis sa sottise !

Et puis, prenez de tels fripons le soin.

Que les parents sont malheureux, qu'il faille

Toujours veiller à semblable canaille !

Qu'ils ont de maux ! et que je plains leur sort !

Ayant tout dit, il mit l'Enfant à bord. ${ }^{1}$ "

«Le Coq et la Perle » est une fable écrite en heptasyllabes :

«Un jour un Coq détourna

Une Perle, qu'il donna

Au beau premier Lapidaire.

"Je la crois fine, dit-il ;

Mais le moindre grain de mil

Serait bien mieux mon affaire. ${ }^{2}{ }^{2}$

En examinant le livre premier des fables, nous remarquons que $\mathrm{La}$ Fontaine présente une série de poèmes où les vers sont de différentes sortes. Ce moyen poétique est évident dans le tableau ci-dessous :

${ }^{1}$ La Fontaine (Jean de), “CEuvres Complètes”, Op.cit., P. 81.

${ }^{2}$ Loc.cit. 


\begin{tabular}{|l|l|}
\hline Le mètre & Le poème \\
\hline L'alexandrin & $\begin{array}{l}\text { Le Corbeau et le Renard, La Grenouille qui veut se } \\
\text { faire aussi grosse que le Bœuf, Les deux Mulets, Le } \\
\text { Loup et le Chien, La Génisse, la Chèvre et la Brebis } \\
\text { en société avec le Lion, La Besace, L'Hirondelle et } \\
\text { les Petits Oiseaux, Le Loup et l'Agneau, L'Homme } \\
\text { et son image, Le Dragon à plusieurs têtes et le } \\
\text { Dragon à plusieurs queues, Les Voleurs et l'Âne, } \\
\text { Simonide préservé par les Dieux, La Mort et le } \\
\text { Malheureux, La Mort et le Bûcheron, L'Homme } \\
\text { entre deux âges et ses deux Maîtresses, Le Renard } \\
\text { et la Cigogne, Les Frelons et les Mouches à miel, } \\
\text { Le Chêne et le Roseau }\end{array}$ \\
\hline $\begin{array}{l}\text { Le } \\
\text { décasyllabe }\end{array}$ & $\begin{array}{l}\text { Les deux Mulets, Le Loup et l'Agneau, L'Homme } \\
\text { entre deux âges et ses deux Maîtresses, L'Enfant et } \\
\text { le Maître d'école }\end{array}$ \\
\hline L'octosyllabe & $\begin{array}{l}\text { Le Corbeau et le Renard, La Grenouille qui veut se } \\
\text { faire aussi grosse que le Bøuf, Les deux Mulets, Le } \\
\text { Loup et le Chien, La Génisse, la Chèvre et la Brebis } \\
\text { en société avec le Lion, La Besace, L'Hirondelle et } \\
\text { les Petits Oiseaux, Le Loup et l'Agneau, L'Homme } \\
\text { et son image, Le Dragon à plusieurs têtes et le } \\
\text { Dragon à plusieurs queues, Les Voleurs et l'Âne, } \\
\text { Simonide préservé par les Dieux, La Mort et le } \\
\text { Malheureux, La Mort et le Bûcheron, L'Homme } \\
\text { entre deux âges et ses deux Maîtresses, Le Renard } \\
\text { et la Cigogne, Les Frelons et les Mouches à miel, } \\
\text { Le Chêne et le Roseau }\end{array}$ \\
\hline La Mort et le Malheureux \\
\hline L'hexasyllabe
\end{tabular}

Cette variation des mètres vise à ne pas lasser le lecteur ainsi qu'elle insiste sur la loi que la forme et le fond se complètent. Dans «Le Bucheron et Mercure », par exemple, le fabuliste utilise presque tous les mètres, alexandrins, heptasyllabique, octosyllabique, décasyllabique. Cherchant à honorer la noblesse du comte de Brienne, il emploie l'alexandrin : 
« Je le veux comme vous : cet effort ne peut plaire. Un auteur gâte tout quand il veut trop bien faire.

Non qu'il faille bannir certains traits délicats :

Vous les aimez, ces traits ; et je ne les hais pas. »

On y trouve aussi quelques octosyllabes qui incarnent la modestie de cette dédicataire :

« J'y tombe au moins mal que je puis.

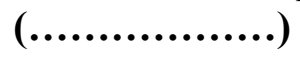

Comme la force est un point

Dont je ne me pique point, $»^{2}$

Avec tout son argent et toute sa volonté, on ne doit pas chercher à changer son statut social. Par la variété des mètres, le fabuliste présente ce conflit inégal entre les bourgeois et les nobles. Afin de décrire la petitesse de la grenouille (les bourgeois), il utilise l'octosyllabe :

«Une Grenouille vit un Bouf Qui lui sembla de belle taille.

Envieuse, s'étend, et s'enfle, et se travaille,

Pour égaler l'animal en grosseur,

Disant : « Regardez bien, ma sour ;

S'enfla si bien qu'elle creva.

Tout petit prince a des ambassadeurs,

Tout marquis veut avoir des pages. ${ }^{3}$

Tandis que l'alexandrin illustre la vanité démesurée de la grenouille qui cherche vainement à se grossir :

«Elle, qui n'était pas grosse en tout comme un ouf,

Est-ce assez ? Dites-moi ; n'y suis-je point encore ?

- Nenni. - M'y voici donc ? - Point du tout. - M'y voilà ?

- Vous n'en approchez point. » La chétive pécore

Le monde est plein de gens qui ne sont pas plus sages :

Tout bourgeois veut bâtir comme les grands seigneurs, » ${ }^{4}$

${ }^{1}$ La Fontaine (Jean de), “Euures Complètes”, Op.cit., P. 104.

${ }^{2}$ Loc.cit.

${ }^{3}$ Ibid., P. 75.

${ }^{4}$ Loc.cit. 
Outre la variété des mètres, les effets de décalage sont aussi nombreux. La Fontaine nous présente un rythme souple, avec la présence de rejets :

«Vos pareils y sont misérables,

Cancres, hères, et pauvres diables ${ }^{1}$ »

Dit-il aussi :

« Dès que vous verrez que la terre

Sera couverte, et qu'à leurs blés ${ }^{2}$ »

Il ajoute :

«Ne trouvant plus rien qui l'étaie, Tombe sur le festin, brise plats et flacons ${ }^{3}$ »

Le phénomène d'enjambement parait aussi présent dans ces récits. La Fontaine dit :

Dit-il aussi :

«Sans mentir, si votre ramage

Se rapporte à votre plumage ${ }^{4}$ »

« Entre en propos, et lui fait compliment

Sur son embonpoint qu'il admire ${ }^{5}$ »

Le poète ajoute :

"Qui causera dans la saison

Votre mort ou votre prison. ${ }^{6}$ "

Cette variété rythmique a pour but d'insister sur la profondeur de la pensée du fabuliste dont la fable doit apporter un enseignement. C'est l'objectif qu'il l'a écrit dans sa « Préface au Dauphin »:

${ }^{1}$ La Fontaine (Jean de), “EEuvres Complètes”, Op.cit., P. 76.

${ }^{2}$ Ibid. P. 77.

${ }^{3}$ Ibid. P. 79.

${ }^{4}$ Ibid. P. 75.

${ }^{5}$ Ibid. P. 76.

${ }^{6}$ Ibid. P. 77. 
« Je chante les héros dont Esope est le père :

Troupe de qui l'histoire, encor que mensongère,

Contient des vérités qui servent de leçons.

Tout parle en mon ouvrage, et même les poissons.

Ce qu'ils disent s'adresse à tous tant que nous sommes. Je me sers d'animaux pour instruire les hommes. ${ }^{1}$ »

D'ailleurs, La Fontaine s'efforce de sonoriser la voix des êtres ${ }^{2}$. Les sonorités apparaissent donc comme l'un des outils de l'expressivité qui renforce la poétique de La Fontaine. Afin de souligner l'agressivité, la violence et la cruauté du loup envers l'agneau, le poète emploie les allitérations en $[\mathrm{d}],[\mathrm{t}],[\mathrm{r}]$ et $[\mathrm{k}]$ :

«Qui te rend si hardi de troubler mon breuvage?

Dit cet animal plein de rage :

Tu seras châtié de ta témérité.

- Sire, répond l'Agneau, que Votre Majesté

Ne se mette pas en colère ;

Mais plutôt qu'elle considère

Que je me vas désaltérant

Dans le courant,

Plus de vingt pas au-dessous d'elle ;

Et que par conséquent, en aucune façon,

Je ne puis troubler sa boisson. ${ }^{3}$ »

Les sonorités jouent aussi un rôle central à incarner le conflit intellectuel entre le chien (l'esclavage) et le loup (la liberté). En soulignant la violence du loup, le poète utilise l'allitération en [k] : «l'attaquer, le mettre en quartier». Ces sonorités deviennent douces (les allitérations en [m- 1] et les assonances en [en- on]) quand le loup cherche à flatter le chien :

« Le Loup donc l'aborde humblement, Entre en propos, et lui fait compliment Sur son embonpoint, qu'il admire. ${ }^{4}{ }^{\star}$

\footnotetext{
${ }^{1}$ Fiechi (Hélène), « Jean de La Fontaine, Fables », Op.cit., P. 32.

${ }^{2}$ Leichter (Frédéric), « Fables », Bréal. Paris, 1997, P. 35.

${ }^{3}$ La Fontaine (Jean de), “CEuvres Complètes”, Op.cit., P. 78.

${ }^{4}$ Ibid. P. 76.
} 
Le poète emploie tous ces procédés poétiques, il dessine des dialogues vivants ainsi qu'il nous raconte des histoires intéressantes, tout cela pour donner une leçon morale capable de toucher le lecteur.

\section{II- La moralité :}

Le récit se relie complètement à la morale. C'est ce que le poète affirme en disant :

\section{«Une morale nue apporte de l'ennui : Le conte fait passer le précepte avec lui. ${ }^{1}{ }^{»}$,}

Dit-il aussi :

\section{« En ses sortes de feintes il faut instruire et plaire Et conter pour conter me semble peu d'affaire ${ }^{2} »$.}

Le lecteur des fables de La Fontaine peut observer qu'elles se caractérisent de la précision de la description, de la virtuosité de l'exposition, de la compétence du dessin des événements. Ici, les trois questions importantes qui ont besoin de répondre : Quel rôle joue la place de la morale dans les fables ? Comment la morale est-elle présentée dans les fables ? Il y a un paradoxe entre les arguments convaincants des faibles et la victoire inévitable des forts? En cherchant la réponse, nous pouvons affirmer que la variété représente la caractéristique principale de la moralité :

\section{1- Place des morales :}

Pour éviter d'ennuyer ses lecteurs, La Fontaine s'emploie à varier le plus possible la formulation et la position de la morale dans une fable. Afin de connaître le rôle que la place de la moralité peut jouer au sein du récit par rapport à ce que vise Jean de La Fontaine, c'est-àdire enseigner une leçon, nous analyserons certaines fables qui nous poussent à toucher cette vérité : la place de la morale présente dans ces récits n'est pas toujours placée au même endroit. Elle apparait parfois avant le récit. Au début de la fable «Le Loup et l'Agneau », La Fontaine, affirmant la cause de l'injustice, commence ainsi :

\footnotetext{
${ }^{1}$ Saulnier (V.L.), « Contes et discours bigarrés », PUPS, Paris, 2011, P. 53.

${ }^{2}$ Ibid. P. 110.
} 
«La raison du plus fort est toujours la meilleure :

Nous l'allons montrer tout à l'heure.

Le loup l'emporte et puis le mange, Sans autre forme de procès. ${ }^{1}$ »

Sous des formes différentes, l'auteur place sa moralité en début de fable. Dans L'Oracle et l'impie, utilisant l'humour, il dit :

«Vouloir tromper le Ciel, c'est folie à la Terre ; $^{2}$ »

Dans «Le mal marié », il présente une morale qui semble opposée au récit attendu :

«Que le bon soit toujours camarade du beau

Dès demain je chercherai femme ${ }^{3}$ »

Dans «Le lion et le Rat», il expose au début sa leçon morale :

«Il faut, autant qu'on peut, obliger tout le monde :

On a souvent besoin d'un plus petit que soi.

De cette vérité deux Fables feront foi,

Tant la chose en preuves abonde. ${ }^{4}$ »

Après la moralité, le récit se présente aussi comme des événements inattendus. C'est ce que le fabuliste donne dans "L'ivrogne et sa Femme » :

«Chacun a son défaut où toujours il revient ${ }^{5}$ "

${ }^{1}$ La Fontaine (Jean de), “CEuvres Complètes”, Op.cit., P. 78.

${ }^{2}$ Ibid. P. 103.

${ }^{3}$ Ibid. P. 118.

${ }^{4}$ Ibid. P. 85.

${ }^{5}$ Ibid. P. 92. 
De plus, la méditation philosophique est l'une des idées qui parait dès le premier vers comme l'a écrit La Fontaine dans «La Mort et le Mourant »:

\section{« La Mort ne surprend point le Sage ${ }^{1}$ »}

Comme dans le Lièvre et la Tortue, le poète commence sur cette célèbre formule :

\section{« Rien ne sert de courir, il faut partir à point ${ }^{2}$ »}

La moralité peut aussi conclure le texte. Dans "Le Corbeau et le Renard", La Fontaine expose la morale par le Renard à la fin du texte :

\section{« Tout flatteur \\ Vit aux dépens de celui qui l'écoute. ${ }^{3}$ »}

La fable de «Les deux mulets » représente aussi un exemple où le poète exprime clairement le fond de sa pensée que la vanité et l'orgueil ne sont pas toujours récompensés :

\section{« Si tu n'avais servi qu'un Meunier, comme moi,}

Tu ne serais pas si malade ${ }^{4}$.»

De cette même manière, il ajoute dans «Le Cochet, le Chat et le Souriceau » :

\section{« Garde-toi, tant que tu vivras, \\ De juger des gens sur la mine. ${ }^{5}$ »}

Dans «Le meunier, son fils et l'âne », La Fontaine dit :

«Quant à vous, suivez Mars, ou l'Amour, ou le Prince ; Allez, venez, courez; demeurez en province ;

${ }^{1}$ La Fontaine (Jean de), “CEuvres Complètes”, Op.cit., P. 126.

${ }^{2}$ Ibid. P. 113.

${ }^{3}$ Ibid. P. 75.

${ }^{4}$ Ibid. P. 76.

${ }^{5}$ Ibid. P. 112. 
Prenez femme, abbaye, emploi, gouvernement :

Les gens en parleront, n'en doutez nullement. ${ }^{1}$ "

« La Mort et le Bûcheron » donne aussi cet exemple :

« Plutôt souffrir que mourir,

C'est la devise des hommes. ${ }^{2}$ "

Ainsi, dans «LaGrenouille qui se veut faire aussi grosse que le bœuf », les derniers vers sont consacrés à l'évocation de la morale :

« Le monde est plein de gens qui ne sont pas plus sages.

Tout bourgeois veut bâtir comme les grands seigneurs,

Tout petit prince à des ambassadeurs,

Tout marquis veut avoir des pages. ${ }^{3}$ »

Dans « Les deux mulets », il dit en conclusion :

«Il n'est pas toujours bon d'avoir un haut emploi :

Si tu n'avais servi qu'un meunier, comme moi,

Tu ne serais pas si malade. ${ }^{4} »$

Dans «Les Animaux malades de la peste », la morale est aussi donnée en conclusion du texte :

«Selon que vous serez puissant ou misérable

Les jugements de cour vous rendront blanc ou noir ${ }^{5} »$.

C'est le même cas que le poète évoque dans «L'homme et son image $»$ :

« Tant de miroirs, ce sont les sottises d'autrui,

Miroirs, de nos défauts les peintres légitimes ;

Et quant au canal, c'est celui

Que chacun sait, le livre des Maximes. ${ }^{6}$ "

${ }^{1}$ La Fontaine (Jean de), “CEuvres Complètes”, Op.cit.,P. 89.

${ }^{2}$ Ibid. P. 79.

${ }^{3}$ Ibid., P. 75.

${ }^{4}$ Ibid. P. 76.

${ }^{5}$ Ibid. P. 118.

${ }^{6}$ Ibid. P. 78. 
Dans «Le renard et le bouc », le poète finit toute la scène par la morale qui dit :

\section{« En toute chose il faut considérer la fin. ${ }^{1}$ »}

Il arrive aussi que la morale se glisse à l'intérieur du récit. Dès le titre jusqu'à la fin du texte, la morale domine toute la scène de «la Besace» où le poète montre que nous sommes forts quand nous suivons les défauts des autres mais nuls pour voir les nôtres :

« Jupiter dit un jour : «Que tout ce qui respire

S'en vienne comparaître aux pieds de ma grandeur :

Si dans son composé quelqu'un trouve à redire,

Il peut le déclarer sans peur ;

Je mettrai remède à la chose ${ }^{2}$ »

Ajoute-il :

\section{«Le fabricateur souverain}

Nous créa besaciers tous de même manière,

Tant ceux du temps passé que du temps d'aujourd'hui :

Il fit pour nos défauts la poche de derrière,

Et celle de devant pour les défauts d'autrui. ${ }^{3}$ "

Il est donc évident que la position de la morale change. Aucune règle précise peut affirmer cette place. Tantôt, elle est donnée avant le récit, tantôt celle-ci se trouve à la fin du récit, tantôt, nous pouvons trouver la moralité au milieu de la fable. La Morale peut aussi être placées à la fois en début et en fin de la fable. Dans « Démocrite et les Abdéritains », le lecteur peut voir le fabuliste se fâche dès le début:

«Que j'ai toujours haï les pensers du vulgaire! ${ }^{4}$ »

\footnotetext{
${ }^{1}$ La Fontaine (Jean de), “CEuvres Complètes”, Op.cit., P. 91.

${ }^{2}$ Ibid., P. 76.

${ }^{3}$ Loc. cit.

${ }^{4}$ Ibid. P. 138.
} 
A la fin du texte, il questionne :

« En quel sens et donc véritable... Que sa voix est la voix de Dieu ? $^{1} »$

Dans «L'âne et le petit chien », le fabuliste commence par la morale :

« Ne forçons point notre talent,

Nous ne ferions rien avec grâce ${ }^{2}$ »

De même, il finit cette scène en disant :

« L'âne change de ton.

Ainsi finit la comédie ${ }^{3}$ »

Dans «Le Paysan du Danube », La Fontaine formule un précepte au début :

«Il ne faut point juger des gens sur l'apparence ${ }^{4}$ »

Le texte se termine par une réflexion :

«On ne sut pas longtemps à Rome

Cette éloquence entretenir ${ }^{5}$ »

À travers la multiplicité de la place de la moralité dans la fable, le poète vise à réaliser ces trois objectifs :

- L'élargissement du sens :

« Hélas! On voit que de tout temps

Les petits ont pâti des sottises des grands ${ }^{6}$ »

${ }^{1}$ La Fontaine (Jean de), “CEuvres Complètes”, Op.cit., P.138.

${ }^{2}$ Ibid. P. 98.

3 Ibid.,P. 98.

${ }^{4}$ Ibid. P. 159.

${ }^{5}$ Loc.cit.

${ }^{6}$ Ibid. P. 83. 
- La généralisation :

\section{«Plutôt souffrir que mourir, C'est la devise des hommes ${ }^{1}$ »}

- Considérer le lecteur en tant qu'un partenaire :

\section{«Quel esprit ne bat pas la campagne Qui ne fait châteaux en Espagne $?^{2}{ }^{2}$}

La deuxième question à laquelle on essaye de répondre dans les lignes suivantes: La Fontaine nous expose directement ou indirectement la moralité du texte?

\section{2- Implicite et explicite des morales :}

Ce qui est intéressant dans une fable, c'est sa dimension morale. Parfois la morale est citée au début ou reprise à la fin comme nous l'avons montré ; il arrive enfin que le conte nous présente l'histoire des animaux, des hommes ou même des plantes qui se luttent pour nous apprendre une leçon de sagesse ${ }^{3}$ celle-ci peut être implicite ou explicite. Tout d'abord, nous pouvons affirmer que la morale de la fable est souvent explicite. C'est le cas de la morale de "Le Lièvre et la Tortue" de La Fontaine :

\section{«Rien ne sert de courir ; il faut partir à point. ${ }^{4}{ }$ »}

Dans «La Grenouille qui veut se faire aussi grosse que le bœuf », le poète insiste complètement et clairement sur l'idée que l'homme doit rester sage, humble, prendre confiance en soi et rester soi-même sans chercher à imiter les autres car nous sommes tous différents :

\section{«Le monde est plein de gens qui ne sont pas plus sages : \\ Tout bourgeois veut bâtir comme les grands seigneurs, Tout petit prince a des ambassadeurs, Tout marquis veut avoir des pages. ${ }^{5}$ »}

\footnotetext{
${ }^{1}$ La Fontaine (Jean de), “CEuvres Complètes”, Op.cit., P. 79.

${ }^{2}$ Ibid. P. 122.

${ }^{3}$ Leichter (Frédéric), « Fables », Op.cit., P. 42.

${ }^{4}$ La Fontaine (Jean de), “Euvres Complètes”, Op.cit., P. 113.

${ }^{5}$ Ibid. P. 75.
} 
Nous avons toujours le temps de suivre les défauts des autres mais nous sommes satisfaits de notre propre personne, c'est la morale que le poète cherche à montrer sans une place d'ambiguïté dans « $\mathrm{La}$ Besace » :

« Nous nous pardonnons tout, et rien aux autres hommes :

On se voit d'un autre oil qu'on ne voit son prochain.

\section{Le Fabricateur souverain}

Nous créa Besaciers tous de même manière,

Tant ceux du temps passé que du temps d'aujourd'hui

Il fit pour nos défauts la poche de derrière, Et celle de devant pour les défauts d'autrui. ${ }^{1}$ "

A travers les répliques du Loup et de l'Agneau, La fontaine annonce son mépris de l'injustice. Le plus fort a toujours raison, non pas parce que ses arguments sont "meilleurs", mais parce qu'il emporte la force sur la raison, sur la vérité et sur le droit :

\section{«La raison du plus fort est toujours la meilleure. ${ }^{2}$ »}

Le loup triomphe, mais sa victoire est injuste et injustifiée. Le lecteur se trouve donc devant deux morales, l'une qui correspond à la victoire du loup est fausse, tandis que la vraie morale que La Fontaine évoque implicitement est le procès perdu du loup. Certes le loup gagne puisqu'il mange l'agneau à la fin, mais il perd la sympathie du lecteur car ses arguments sont illogiques. Deux expressions montrent l'adoption du narrateur de cette morale :

\section{«Cet animal plein de rage \\ Cette bête cruelle... »}

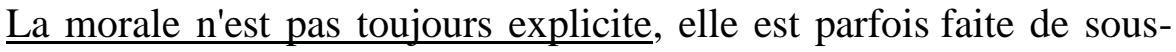
jacent ou de murmures. C'est alors au lecteur de ne pas être dupe, de réfléchir et de déduire ce que veut dire l'écrivain. «...s'il m'est arrivé de le faire, ce n'a été que dans les endroits où elle n'a pu entrer avec grâce, et où il est aise au lecteur de la suppléer. ${ }^{3}$ "

\footnotetext{
${ }^{1}$ I La Fontaine (Jean de), “Euvres Complètes”, Op.cit., P. 76.

2 Ibid., P. 78.

${ }^{3}$ Walckenaer (M.C-A), « Euvres complètes de Jean de La Fontaine », Lefèvre,

Paris, sans date, p. 4.
} 
Dans «La Cigale et la Fourmi», La Fontaine nous présente indirectement le conflit entre deux mondes, la prévoyance de la Fourmi et la jouissance de la Cigale. Alors, il cherche à nous enseigner la leçon qu'on doit être prévoyant pour ne pas être à la merci d'autrui :

\section{«Vous chantiez? J'en suis fort aise. Eh bien dansez maintenant. ${ }^{1}$ "}

Devant la peur de la Guerre, de la Famine, de la misère et du conflit, les responsables dans cet univers préfèrent, au lieu de chercher à résoudre les problèmes, se lancer dans des discussions. Ce message est exposé dans «L'Enfant et le Maître d'école » :

\section{«Dans ce récit je prétends faire voir D'un certain Sot la remontrance vaine. ${ }^{2}$ »}

Parmi les fables qui comportent une morale implicite que le lecteur doit s'efforcer pour tirer, on ne doit pas oublier " L'Homme et son image » où La Fontaine essaie d'une façon plaisante de dénoncer le narcissisme :

\section{«On voit bien où je veux venir. Je parle à tous $; \ldots \ldots . . .{ }^{3}{ }^{\prime}$}

Au temps où le poète nous dit implicitement ce qu'il pense, il nous laisse plusieurs indices qui évoquent le non-dit, parmi lesquels, on cite :

1) L'emploi du pronom personnel «Je » qui permet au poète non seulement de tisser un passage entre le lecteur et lui-même, mais d'élargir le rapport à plusieurs personnes.

2) L'enjambement et l'utilisation du pronom «chacun » soulignent la généralité de la situation :

${ }^{1}$ La Fontaine (Jean de), “CEuvres Complètes”, Op.cit., P. 75.

${ }^{2}$ Ibid., P. 81.

${ }^{3}$ Ibid. P. 78. 


\section{Est un mal que chacun se plaît d'entretenir ${ }^{1}{ }$ '}

3) L'utilisation de la périphrase « conseillers muets » nous indique que les miroirs représentent le reflet qu'on peut se voir :

\section{« Tant de miroirs, ce sont les sottises d'autrui, Miroirs, de nos défauts les peintres légitimes ; \\ Et quant au canal, c'est celui Que chacun sait, le livre des Maximes. ${ }^{2}$ »}

La société française au XVIIe siècle est bien décrite dans les fables de la Fontaine qui, dénonçant la vie politique à cette époque, trace une image de deux mondes méprisés, le courtisan (ici le renard) qui exploite la flatterie pour obtenir ce qu'il veut et le courtisé (le corbeau) qui jouit de ces belles paroles qu'il écoute. En général, on peut affirmer que ces deux classes sociales se dépendent, l'un pour les compliments et l'autre pour les fromages:

\section{«Apprenez que tout flatteur}

\section{Vit aux dépens de celui qui l'écoute. ${ }^{3}$ »}

Beaucoup de vues philosophiques regardent la campagne comme un asile contre le bruit et l'angoisse. La Fontaine n'oublie pas de rappeler ce principe. Dans son apologue « Le rat de ville et le Rat des champs », il exprime implicitement son attachement à la vie tranquille de la campagne :

\section{«Adieu donc ; fi du plaisir Que la crainte peut corrompre. ${ }^{4} »$}

Dans "Le loup et le chien", le fabuliste incarne deux mondes opposés, le chien est riche et bien nourri, mais il est enchaîné, tandis que le loup maigre et affamé va où il veut. Cette comparaison nous explique le non-dit de la morale de cette fable qu'on peut résumer

\footnotetext{
${ }^{1}$ La Fontaine (Jean de), “CEuvres Complètes”, Op.cit., P.78.

${ }^{2}$ Loc.cit.

3 Ibid., P. 75.

${ }^{4}$ Ibid. P. 77.
} 
ainsi : il est mieux d'être pauvre, affamé et libre que d'être riche, bien nourri mais esclave. La liberté n'a donc pas de prix:

«Chemin faisant il vit le col du Chien, pelé : Qu'est-ce là? lui dit-il. Rien. Quoi ? Rien ? Peu de chose.

Mais encor? Le collier dont je suis attaché

De ce que vous voyez est peut-être la cause.

Attaché ? dit le Loup : vous ne courez donc pas

Où vous voulez? Pas toujours, mais qu'importe?

Il importe si bien, que de tous vos repas

Je ne veux en aucune sorte,

Et ne voudrais pas même à ce prix un trésor. »

La fin ouverte de la scène montre la supériorité et la victoire du loup :

«Cela dit, maître Loup s'enfuit, et court encor. ${ }^{1}$ "

La leçon ici est qu'on doit être soi-même. Cette vision implicite affirme le contrepoint des fables de La Fontaine. «Le loup et le chien » parait une relecture de «la grenouille qui veut se faire aussi grosse que le bœuf ». Comme la grenouille, le loup s'efforce pour être quelqu'un d'autre. Après plusieurs tentatives, les deux arrivent à la vérité que ce changement est impensable. Devant cette variété philosophique, politique, sociale et familiale des messages que le lecteur s'efforce de déduire, on doit insister sur l'idée que le moraliste, pour ne pas nous lasser, fait également varier les manières d'exprimer la moralité qui peut apparaitre à travers :

A) L'opinion des héros :

\section{«L'on tomba d'accord}

Qu'à peu de gens convient le diadème ${ }^{2}$ »

B) L'expression directe de la leçon :

«Ceci s'adresse à vous, esprits du dernier ordre » ${ }^{3}$

En instruisant ses lecteurs, il dit :

${ }^{1}$ La Fontaine (Jean de), “CEuvres Complètes”, Op.cit., P. 76.

${ }^{2}$ Ibid. P. 112.

${ }^{3}$ Ibid. P. 108. 
«La raison du plus fort est toujours la meilleure :

Nous l'allons montrer tout à l'heure »

Pour les avertir, il cite :

«Trompeurs, c'est pour vous que j'écris ${ }^{1}{ }^{\star}$

Pour conseiller, il ajoute :

«Patience et longueur de temps

Font plus que force ni que rage ${ }^{2}$ »

C) L'utilisation d'une métaphore :

« Ce chef passe, et le corps, et chaque queue aussi :

Rien ne les empêcha; l'un fit chemin à l'autre.

Je soutiens qu'il en est ainsi

De votre Empereur et du nôtre. ${ }^{3}$ »

D) L'exploitation du personnage principal. Lorsque la souris parle au souriceau, elle dit :

« Garde-toi... de juger les gens sur la mine ${ }^{4}$ »

De même, l'ours dit au vantard :

«Il ne faut jamais

Vendre la peau de l'Ours $»^{5}$

E) Pour faire approfondir sa leçon, La Fontaine insiste sur l'idée qu'un dieu peut enseigner la leçon :

\section{« Hercule crie "Aide-toi, le Ciel t'aidera ${ }^{6}$ »}

La variété des places, du contenu et des formules d'expression de la moralité traduit la philosophie de La Fontaine qui a décrit la vie telle qu'elle est : la force, la faiblesse, la richesse, la pauvreté, le mal et le

${ }^{1}$ La Fontaine (Jean de), “Euvres Complètes”, Op.cit., P. 80.

${ }^{2}$ Ibid. P. 85.

${ }^{3}$ Ibid.P. 78.

${ }^{4}$ Ibid. P. 112.

${ }^{5}$ Ibid. P. 110.

${ }^{6}$ Ibid. P. 115. 
bien et toutes les couleurs de la vie. Cela se reflète à travers le conflit continu entre les arguments présentés et le paradoxe dans le texte : malgré sa croyance de l'innocence et la bonté des faibles, l'auteur ne permet pas aux faibles de se soumettre aux forts, ni aux pauvres d'échapper de l'esclavage des riches. Dans ce contexte, on peut classer ces argumentations en trois types ${ }^{1}$ :

1) Les argumentations internes qui sont menées par les héros de la fable. Ces humains ou ces animaux défendent une idée. Dans ce domaine, ils peuvent acquérir ou perdre. Dans «Le loup et l'agneau », «Le chat, la belette et le petit lapin » ou «l'homme et la couleuvre », le fabuliste nous présente le même tableau : un rapport inégal entre les faibles qui ont toujours raison et les puissants qui n'ont que le droit du plus fort. Cette lutte se termine par la victoire de l'illogique. Le loup et le chat ne cherchent pas à savoir qui a raison, de l'agneau ou du lapin, mais ils pensent seulement à les manger. Ce genre d'argumentation apparaît aussi dans «Les obsèques de la lionne ». Malgré la différence de la situation, la mauvaise foi est le moteur principal des événements. L'essentiel est de réaliser l'intérêt non de faire triompher la vérité : le cerf est menacé de mort parce qu'il n'est pas présent au deuil de la reine. Alors cet animal est obligé, pour se sauver, de mentir. Il a vu la lionne défunte en rêve, il n'y a plus lieu de pleurer puisqu'elle est heureuse au paradis.

2) Les argumentations externes où le fabuliste, pour montrer la moralité, dépend sur des exemples ou de petites histoires. Dans «Le loup et l'agneau », il commence par la morale, « la raison du plus fort est toujours le meilleur», avant de préciser le récit, "nous l'allons montrer tout à l'heure ». C'est aussi le cas de la fable « Le paysan du Danube » où l'écrivain énonce la moralité puis l'illustre :

« Il ne faut point juger des gens sur l'apparence. Le conseil en est bon ; mais il n'est pas nouveau. Jadis l'erreur du souriceau Me servit à prouver le discours que j'avance. J'ai pour le fonder à présent Le bon Socrate, Esope et certain Paysan Des rives du Danube, homme dont Marc-Aurèle Nous fait un portrait fort fidèle. ${ }^{2}$ "

\footnotetext{
${ }^{1}$ Cf. Fiechi (Hélène), « Jean de La Fontaine, Fables », Op.cit., PP. 271-275.

${ }^{2}$ La Fontaine (Jean de), “EEuvres Complètes”, Op.cit., P. 159.
} 
3) Les argumentations implicites où le récit peut être flou. Pour l'auteur, chacun de nous doit en tirer plusieurs conclusions. La vérité absolue n'existe pas. C'est l'état de la controverse que La Fontaine présente dans « Le loup et le renard »:

« Mais d'où vient qu'au renard Esope accorde un point,

C'est d'exceller en tours pleins de matoiserie ?

$J$ 'en cherche la raison, et ne la trouve point.

Quand le loup a besoin de défendre sa vie,

Ou d'attaquer celle d'autrui,

N'en sait-il pas autant que lui ?

Je crois qu'il en sait plus ; et j'oserais peut-être Avec quelque raison contredire mon maître. ${ }^{1}$ "

\section{3) Le paradoxe dans le texte (Incarnation de la réalité) :}

Tout d'abord, nous pouvons dire que La fontaine nous présente des maximes qui reflètent à la fois des vérités générales et des valeurs intemporelles comme le conseil de la prudence, l'évitement des hypocrites, la punition des sottises, la lutte contre le désespoir et l'appel au travail. Ces valeurs qu'il conseille s'opposent aux vérités qu'il personnifie dans son texte. Afin de conseiller les lecteurs et de leur donner un meilleur avenir, le fabuliste trace des portraits méprisés mais réels : les forts imposent leur loi au détriment des faibles. Ils ne pensent que tout est créé pour eux. Ils ont tous les droits :

«Ce droit, vous le savez, c'est le droit du plus fort. ${ }^{2}$ »

Le désespoir pousse souvent l'homme à souhaiter la mort. Mais, quand on revient à la réalité, le refus de la mort apparait comme l'espoir souhaité. C'est ce que l'écrivain finit son histoire « La Mort et le Malheureux » :

«Ne viens jamais, ô Mort ! On t'en dit tout autant. ${ }^{3}$ » Malgré ces circonstances difficiles que l'homme rencontre dans cette vie, le poète réaffirme son refus de la mort :

${ }^{1}$ La Fontaine (Jean de), “CEuvres Complètes”, Op.cit., P. 166.

${ }^{2}$ Ibid. P. 76.

${ }^{3}$ Ibid. P. 79. 
« Plutôt souffrir que mourir,

C'est la devise des hommes. ${ }^{1}$ »

A côté de ces valeurs générales, les morales sont aussi datées et dirigées contre des actions et des hommes précis. En décrivant la domination des menteurs, des hypocrites, des flatteurs et des rusés de la cour pendant le règne de Louis XIV, le poète consacre plusieurs scènes, parmi elles, on peut citer "Le Corbeau et le Renard », "Le Renard et la Cigogne » et «Le Loup et le Chien». Pour lui, le courtisan doit, pour survivre, savoir louvoyer, flatter, être hypocrite :

« Hé ! Bonjour, monsieur du Corbeau.

Que vous êtes joli ! Que vous me semblez beau !

Sans mentir, si votre ramage

Se rapporte à votre plumage,

Vous êtes le phénix des hôtes de ces bois. ${ }^{2}$ »

A travers ce mélange des personnages, le fabuliste nous présente la folie humaine. Dans « Le rat et l'huître », il critique la vanité :

« Certes, dit-il, mon père était un pauvre sire !

Il n'osait voyager, craintif au dernier point.

Pour moi, j'ai déjà vu le maritime empire :

J'ai passé les déserts, mais nous n'y bûmes point.

D'un certain magister le Rat tenait ces choses,

Et les disait à travers champs ;

N'étant pas de ces rats qui les livres rongeants

Se font savants jusques aux dents. ${ }^{3}$ »

La punition de la vanité est toujours inévitable :

« Je dois faire aujourd'hui bonne chère, ou jamais.

Là-dessus maître Rat plein de belle espérance,

Approche de l'écaille, allonge un peu le cou,

Se sent pris comme aux lacs; car l'Huître tout d'un coup

Se referme, et voilà ce que fait l'ignorance. ${ }^{4}$ »

${ }^{1}$ La Fontaine (Jean de), “CEuvres Complètes”, Op.cit., P. 79.

${ }^{2}$ Ibid. P. 75.

${ }^{3}$ Ibid. P. 130.

${ }^{4}$ Loc.cit. 
Parmi les défauts graves que l'auteur cherche aussi à refuser, c'est aussi l'insatisfaction qui pousse l'homme à amasser toujours plus :

« Je reviens à mon texte. Il faut que l'on jouisse ;

Témoin ces deux gloutons punis d'un sort commun ;

La convoitise perdit l'un ;

L'autre périt par l'avarice. ${ }^{1}{ }^{\prime}$

L'écrivain met aussi en garde l'ami ignorant :

« Rien n'est si dangereux qu'un ignorant ami;

Mieux vaudrait un sage ennemi. ${ }^{2}{ }^{\text {» }}$

Cependant, tout n'est pas sombre. Malgré la moquerie des faibles, la fable n'est pas sans référence à la moralité. La Fontaine y expose des exemples lumineux. Outre l'orgueil, la vanité, l'ignorance, l'insatisfaction, la ruse l'avidité, les sages apparaissent aussi sous les traits de conseillers :

«Du fil et du soufflet pourtant embarrassé,

Un des dupes un jour alla trouver un sage,

Qui, sans hésiter davantage,

Lui dit : « Ce sont ici hiéroglyphes tout purs.

Les gens bien conseillés, et qui voudront bien faire,

Entre eux et les gens fous mettront pour l'ordinaire

La longueur de ce fil ; sinon je les tiens sûrs

De quelque semblable caresse.

Vous n'êtes point trompé : ce fou vend la sagesse. ${ }^{3}$ »

La vie est douce à ceux qui savent en jouir. C'est le cas du savetier pauvre, mais heureux :

«Un Savetier chantait du matin jusqu'au soir :

C'était merveilles de le voir,

Merveilles de l'ouïr ; il faisait des passages,

Plus content qu'aucun des Sept Sages. ${ }^{4}$ »

\footnotetext{
${ }^{1}$ La Fontaine (Jean de), “CEuvres Complètes”, Op.cit., P. 138.

${ }^{2}$ Ibid. P. 130.

${ }^{3}$ Ibid. P. 143.

${ }^{4}$ Ibid. P. 127.
} 
Pour la Fontaine, le sentiment d'amour doit l'emporter sur l'égoïsme. C'est l'idée que représente le pigeon non voyageur qui tente d'empêcher le voyage hasardeux de son compagnon :

\section{«L'autre lui dit : Qu'allez-vous faire ?}

Voulez-vous quitter votre frère?

L'absence est le plus grand des maux :

Non pas pour vous, cruel. Au moins, que les travaux,

Les dangers, les soins du voyage,

Changent un peu votre courage. ${ }^{\prime}$ "

La liberté est encore l'un des odes que le moraliste n'oublie pas de chanter. Dans «Le Loup et le Chien», il évoque la leçon que tous doivent enseigner : la liberté est un trésor :

\section{«- Il importe si bien, que de tous vos repas \\ Je ne veux en aucune sorte,}

Et ne voudrais pas même à ce prix un trésor.

Cela dit, maître Loup s'enfuit, et court encore. ${ }^{2}$ "

La lutte entre les qualités et les défauts, entre la sagesse et la folie continue à jamais. Avant tout, le lecteur est invité à profiter de cette expérience qui se base totalement sur le paradoxe qui reflète en effet la paradoxale de la vie. Au temps où le vieil homme s'efforce pour planter des arbres, les jeunes hommes soulignent ces activités avec une certaine méchanceté.

\section{«Un octogénaire plantait.}

Passe encor de bâtir ; mais planter à cet âge !

Disaient trois Jouvenceaux, enfants du voisinage $;^{3}$ "

Mais celui qui avait l'air fou était sage en réalité : selon lui, l'homme doit travailler jusqu'à la fin de sa vie parce qu'on ne connait jamais, d'une part, la date de sa mort, d'autre part, rien ne vaut le plaisir d'œuvrer pour les générations futures :

«Cela même est un fruit que je goûte aujourd'hui : $\mathrm{J}$ 'en puis jouir demain, et quelques jours encore ; Je puis enfin compter l'aurore

\footnotetext{
${ }^{1}$ La Fontaine (Jean de), “CEuvres Complètes”, Op.cit., P. 140.

${ }^{2}$ Ibid. P. 76.

${ }^{3}$ Ibid. P. 160.
} 
Plus d'une fois sur vos tombeaux.

Le Vieillard eut raison ;....... . »

Ces paradoxes apparaissent aussi dans sa fable «Le fou qui vend la sagesse », où le premier paradoxe s'exprime dès le titre tandis que le second paradoxe domine toute la scène : celui qui croit acheter la sagesse est plus fou que le fou :

« Un Fol allait criant par tous les carrefours

Qu'il vendait la sagesse, et les mortels crédules

De courir à l'achat ;...... »

Des exemples qui représentent ce conflit entre les fous et les sages, on peut aussi citer :

\begin{tabular}{|c|c|c|}
\hline Fous & Sages & $\begin{array}{l}\text { Fous et sages à la } \\
\text { fois }\end{array}$ \\
\hline $\begin{array}{l}\text { Le corbeau } \\
\text { L'homme qui court } \\
\text { après la fortune } \\
\text { Le mourant } \\
\text { Le rat } \\
\text { Le loup et le chasseur } \\
\text { Le pigeon qui part en } \\
\text { voyage } \\
\text { Les trois jeunes } \\
\text { hommes }\end{array}$ & $\begin{array}{l}\text { L'homme qui attend la } \\
\text { fortune dans son lit } \\
\text { Le savetier } \\
\text { Le fou qui vend la } \\
\text { sagesse } \\
\text { Le vieillard } \\
\text { Le solitaire } \\
\text { L'interprète }\end{array}$ & $\begin{array}{l}\text { Le lièvre } \\
\text { Le charlatan } \\
\text { Le berger }\end{array}$ \\
\hline
\end{tabular}

Tous ces paradoxes font naitre en nous la réflexion et la méditation. Les fables ne sont pas claires. Elles ont toujours besoin d'une lecture approfondie.

L'auteur invite donc le lecteur d'être le partenaire pour déchiffrer ces histoires et pour résoudre ces énigmes :

«Qui d'eux aimait le mieux, que t'en semble, Lecteur?

Cette difficulté vaut bien qu'on la propose. ${ }^{3}$ "

De tout ce qui précède, nous pouvons affirmer qu'il n'est pas nécessaire que le récit fasse la preuve de la moralité. L'essentiel, pour

${ }^{1}$ La Fontaine (Jean de), “CEuvres Complètes”, Op.cit., P.160.

2 Ibid., P. 143.

${ }^{3}$ Ibid. P. 131. 
le fabuliste, est de peindre la vérité telle qu'elle est sans aucun idéalisme. Dans cette vie, on ne peut toujours tout comprendre ni tout expliquer : on peut avoir la raison mais ne pas l'emporter; on peut avoir le sentiment d'être gagnant alors qu'on perd en vérité. Beaucoup de faits échappent à la raison ou à la logique. Il est donc remarquable que tout est présent dans la fable de La Fontaine: morale explicite, morale implicite, histoire sans fin précise. On y trouve aussi des défauts que le lecteur doit éviter comme la vanité, l'ignorance, la cruauté, l'avarice, l'ambition....des qualités qu'il doit suivre comme le sacrifice, la satisfaction, le travail, la liberté, etc.

Avant de clore cet article, il faut signaler ces trois remarques essentielles:

\section{A) L'originalité du texte :}

Malgré la multitude et l'ancienneté des récits, La Fontaine cherche toujours l'enrichissement et l'originalité de l'œuvre où il subit beaucoup de transformations :

* Afin de mieux présenter la morale, l'écrivain retranche, amplifie, transforme les incidents et les circonstances ainsi qu'il fait une présentation vivante.

* Il présente dans la même fable deux sources différentes (deux valeurs opposées).

* Pour faire de la fable une comédie, les personnages se dialoguent selon leur psychologie.

\section{B) La généralité du récit :}

Pour bien dessiner un portrait de la vie et afin de traiter toutes les questions philosophiques, sociales, familiales, pédagogiques et politiques, le fabuliste présente dans ses récits un panorama des actions dont les héros sont nombreux : 


\begin{tabular}{|c|c|}
\hline Animaux-animaux & $\begin{array}{c}\text { Chat et un vieux rat/ Le Chat, la belette et le petit } \\
\text { lapin/ La cigale et la fourmi/ Le coche et la } \\
\text { mouche/ La colombe et la fourmi/ Le corbeau et le } \\
\text { renard//Les Vautours et les Pigeons /Les deux } \\
\text { Coqs /Le Chat, la Belette et le petit Lapin /La tête } \\
\text { et la queue du Serpent }\end{array}$ \\
\hline Animaux-humains & $\begin{array}{c}\text { Le loup et les bergers/ Le Meunier, son fils et } \\
\text { l'âne/ L'ours et l'amateur des jardins/ Le Coche et } \\
\text { la Mouche/ L'Homme et la Puce/ Le Rieur et les } \\
\text { Poissons /L'Ours et l'Amateur des jardins/ Le } \\
\text { Loup et le Chasseur }\end{array}$ \\
\hline Humains-humains & $\begin{array}{c}\text { Le berger et le roi/ Les deux amis/ Le jardinier et } \\
\text { son seigneur/ Le laboureur et ses enfants/ Le } \\
\text { savetier et le financier }\end{array}$ \\
\hline Humains & $\begin{array}{c}\text { A madame de Montespan/ A Monsieur le duc de } \\
\text { Bourgogne/ La jeune veuve/ Astrologue qui se } \\
\text { laisse tomber dans un puits/ L'avare qui a perdu } \\
\text { son trésor/Le Fou qui vend la sagesse }\end{array}$ \\
\hline Animaux & $\begin{array}{c}\text { Le rat qui s'est retiré du monde/ Conseil tenu par } \\
\text { le rat/ Les obsèques de la lionne/ Le Héron /La } \\
\text { cour du Lion }\end{array}$ \\
\hline Animaux déguisés & $\begin{array}{c}\text { La souris métamorphosée en fille/ Chatte } \\
\text { métamorphosée en femme }\end{array}$ \\
\hline en humains &
\end{tabular}

\section{C) Le non idéalisme de la morale :}

La fontaine n'adopte pas de règles morales qui suivent, ni des buts idéaux à respecter, il cherche toujours à dévoiler la réalité de cette vie sans en chercher une meilleure. Au moment où la victime est privée de l'aide des autres, il ouvre la voie de la victoire inévitable aux puissants. 
Bibliographie

\section{I- Corpus :}

La Fontaine (Jean de), “Euuvres Complètes”, Seuil, Paris, 1965.

\section{II- Ouvrages généraux :}

Bortoli (Véronique Bremond), «Fables, (livres VII à IX) », Hachette, Paris, 2017,

Collinet (Jean-Pierre), «Le monde littéraire de La Fontaine », PUF, Paris, 1970.

Dandrey (Patrick), «La fabrique des fables. Essai sur la poétique de La Fontaine », Klincksieck, coll. " Théorie et critique de l'âge classique », Paris, 1991.

Deschoux (Marcel), «Platon ou le jeu philosophique », Les belles lettres, Paris, 1980.

Fiechi (Hélène), «Jean de La Fontaine, Fables », Gallimard, Paris, 2000.

La Fontaine (Jean), «Les fables», ADL, Montréal, 2015.

Leichter (Frédéric), «Fables », Bréal. Paris, 1997.

Saulnier (V.L.), « Contes et discours bigarrés », PUPS, Paris, 2011.

Van Gennep (Arnold), « Manuel de folklore français contemporain », A. Picard, Paris, 1938.

Walckenaer (M.C-A), « Euvres complètes de Jean de La Fontaine », Lefèvre, Paris, sans date.

\section{III- Articles:}

Dandrey (Patrick), «La fabrique des fables. Essai sur la poétique de La Fontaine », Paris, Klincksieck, coll. « Théorie et critique de l'âge classique », nO 6, 1991.

Scholl (Jules-Charles), « Le Fable et les fabulistes », article, Actes de la Société jurassienne d'émulation, 2019.

Van der Meulen (Emmanuel) \& Zarka (Raphaël), «FABLES, FORMES, FIGURES », Fondation Nationale des Arts Graphiques et Plastiques, juin 2018. 


\section{IV-Sitographie :}

https://www.fondationdesartistes.fr/wp-content/uploads/2019/02/cpFables-Formes-Figures.pdf.

http://lettres-histoiregeo.acamiens.fr/IMG/pdf/la_fable_et_le_conte_pour_argumenter.

classes.bnf.fr/essentiels/grand/ess_869.htm https://openaccess.leidenuniv.nl/bitstream/handle/ http://www.site-magister.com/prepas/fables2.htm\#axzz5kWB0h5De https://books.google.com.eg/books? http://www.site-magister.com/prepas/fables2. manpowergroup.com.br/jolies_fables_de_la_fontaine.pdf 